Research Article

\title{
Improving Menstrual Hygiene Management in School Going Adolescent Girls: Experience from Charutar Region of Gujarat, India
}

\author{
Manisha K Gohel', Ajay G Phatak ${ }^{2}$
}

${ }^{1}$ Professor, Department of Community Medicine, Pramukhswami Medical College, Karamsad, Anand, Gujarat, India. ${ }^{2}$ Professor of Biostatistics \& Adjunct Professor of Public Health, Central Research Services, Charutar Arogya Mandal, Karamsad, Anand, Gujarat, India.

DOI: https://doi.org/10.24321/2349.2880.201912

\section{I $\quad \mathbf{N} \quad \mathbf{F} \quad \mathbf{O}$}

\section{Corresponding Author:}

Ajay G Phatak, Central Research Services, Charutar Arogya Mandal, Karamsad, Anand, Gujarat, India.

E-mail Id:

ajaygp@gmail.com

Orcid Id:

https://orcid.org/0000-0002-8876-8684

How to cite this article:

Gohel MK, Phatak AG. Improving Menstrual Hygiene Management in School Going Adolescent Girls: Experience from Charutar Region of Gujarat, India. Ind J Youth Adol Health 2019; 6(3): 13-19.

Date of Submission: 2020-01-21

Date of Acceptance: 2020-03-06

\section{$\begin{array}{llllllllllllll}\text { A } & \text { B } & \mathbf{S} & \mathbf{T} & \mathbf{R} & \mathbf{A} & \mathbf{C} & \mathbf{T}\end{array}$}

Background: The onset of menstruation is the most important change occurring among girls during the adolescent years. A supportive ecosystem to manage menstruation hygienically and with dignity is a key priority for adolescent girls.

Aim: To understand adolescent girls' knowledge and attitudes about menstruation and empower them with scientific basis of physiology of menstruation and hygiene.

Methods: Four schools were selected and girls in Standard 8 to 10 were included in the study. A pre-test was conducted using a structured questionnaire to assess their knowledge and attitudes about menstruation. The questionnaire included topics concerning physiology of menstruation, menstrual hygiene and beliefs and restrictions related to menstruation. This pre-assessment was followed by an interactive educational intervention using PowerPoint presentation, videos, posters, flip charts and role play. A post-test was conducted and a private consultation session was organized to enable participants to interact with the faculty without fear/ stigma.

Result: Total 360 (359 pre-test and 358 post-test) girls in the age group 12 to 17 years, from 4 schools participated in the study. Most girls [284(79.1\%)] identified menstruation as a normal physiological process. Yet, a sense of impurity leading to social and cultural restrictions was quite prevalent. The knowledge about hygiene practices and common issues during menstruation was poor. The knowledge and attitudes improved significantly after the educational intervention.

Conclusion: Adolescent girls showed poor knowledge and attitudes about menstruation and hygiene. A systematic educational intervention improves MHM of adolescent girls. A comprehensive and contextual adolescent health model including all stakeholders should be developed to improve health of our future generation.

Keywords: Menstrual Hygiene, Education, Adolescent, Girls, Schools 


\section{Introduction}

Onset of menstruation is a natural physiological process. It is an important milestone in woman's life cycle as it signifies the transition from girlhood to womanhood. Women spend an estimated 5-7 years of their life menstruating. However, most major religions and cultures associate menstruation with impurity and impose many socio-cultural and religious restrictions on menstruating woman. All religions propagate avoidance from sexual activity, isolation and prohibiting religious services for a menstruating woman but with varying severity. ${ }^{1}$

Good Menstrual Hygiene ( $\mathrm{MH}$ ) practices like properly washing the genital area and keeping it dry through absorbent material is important during menstruation. Poor $\mathrm{MH}$ practices increase the vulnerability of the females to Reproductive Tract Infections (RTI), ${ }^{2}$ albeit specific infection, route of transmission and strength of effect is unclear. ${ }^{3}$

Adequate knowledge and supporting ecosystem is essential for females to manage menstruation properly without shame. However, menstruation is a taboo in Indian culture. Most girls get inconsistent knowledge about menstruation by family members mainly mothers and that too after they start menstruating. ${ }^{4}$ The shyness in talking about menstruation is so engraved in Indian society that teachers generally omit the topic related to reproductive health. Urban girls turn to Internet to seek information. Femcare industry promoting sanitary pads replace red colour with blue just to be culturally correct. ${ }^{4-5}$ Such ecosystem has a cascading effect and the girls receive inadequate, perplex and unscientific information about the physiology and good menstrual management.

Many studies across India gauged the awareness and practices related to menstruation. All of them unequivocally confirmed poor knowledge and practices ${ }^{6-8}$ with stark rural urban differences. ${ }^{7-8}$ Girls are inquisitive not only about the menstrual health but also about overall health including health and beauty. ${ }^{9}$ The scenario is similar in low- and middle-income countries as well and calls for action in improving Menstrual Health Management (MHM). ${ }^{10-11}$

There have been some successful attempts to improve MHM and comprehensive reproductive health in school-based intervention through conventional and peer education strategies. ${ }^{12-13}$ Few community based studies also reported improvement in MHM (knowledge as well as practices). ${ }^{14-15}$

It is imperative to develop community-based interventions addressing rural populations and school-based programmes catering to urban populations. However, with the decreasing trends in school dropouts in rural areas coupled with availability of a tested framework of intervention, a schoolbased MHM programme can be a starting point. ${ }^{16-17}$

A contextual school-based programme was conducted to check impact of such intervention on MHM and to understand reproductive health from the lens of adolescent girls in schools of Anand, Gujarat.

\section{Material and Methods}

The study was started as an experiment of opportunity when school principals felt the need of empowering girls about MHM almost a decade ago. The process was formalized in the due course by the Government of Gujarat under various programmes like Adolescents Reproductive \& Sexual Health (ARSH) under second phase of Reproductive and Child Health (RCH-II) followed by Rashtriya Kishor Swasthya Karyakram (RKSK) in 2014. ${ }^{18}$ A representative data of four schools where the sessions were conducted in January to April 2015 is presented. The study was approved by institutional ethics committee.

'Adolescent Health' sessions were conducted for girls of $8^{\text {th }}$ to $10^{\text {th }}$ standard in schools of Anand, Gujarat. All the girls present on the day of the session were included in the study after obtaining informed consent for the anonymous use of the data. The contents were developed keeping in mind the components of RKSK programme. Broadly, four main topics were covered

- Physiology: Changes in breast, hair growth, etc

- Menstrual cycle: Physiology, and associated complaints like pre-menstrual syndrome

- Nutrition and Anaemia: Importance of nutrition, anaemia prevention and management

- Role of exercise and Yoga in management of menstruation

The session consisted of didactic lectures using power point presentation and flip charts, pertinent videos as well as role plays. This was followed by a 'Question \& Answer' session. Girls were encouraged to ask questions. To make them comfortable, a box was placed in the room and the girls were asked to put the questions in writing in the box anonymously. A personal discussion was also arranged for those who were shy and hesitated asking their questions even anonymously.

A structured questionnaire covering basic demographic data and topics concerning menstrual hygiene, beliefs and restrictions related to menstruation was designed, consensually validated and pretested. The questionnaire evolved over time and final form was achieved in 2013-14. The questionnaire was administered before the session and after the doubt clearing session. The questions in the doubt clearing session and personal discussions were noted. The questionnaire was developed in English and then translated and back translated in vernacular (Gujarati) language and English respectively by an expert who had a flavor of local dialect to ensure the accuracy and face validity of the questionnaire. The questionnaire consisted of 11 multiple choice questions and 8 true/false questions. 
Sample Size: In absence of reliable estimates in this region, we assumed that the girls have about $50 \%$ correct knowledge about MHM. To estimate a proportion of $50 \%$, a random sample of about 400 was required with $95 \%$ confidence level and 5\% acceptable difference. We expected about $350+$ participants would consent for the participation from 4 schools.

Statistical Analysis: Descriptive Statistics [mean (SD), frequency (\%)] was used to depict the characteristics of the participants. Test of difference between proportion was used to compare the baseline differences across residential status (rural vs urban). Due to anonymity of participants, McNemar's test could not be performed and, hence, test of difference between proportion was used to assess improvement (if any) in knowledge, attitude and practices related to menstruation. Common themes were extracted from doubt clearing sessions and personal discussions and the gist is presented. The quantitative analysis was performed using STATA (Version 14.2, Stata Corporation,
Texas, USA) whereas the analysis of qualitative data was performed manually. A p-value less than 0.05 was considered statistically significant.

\section{Result}

Total 360 (359 pre-test and 358 post-test) girls in the age group 12 to 17 years, from 4 schools participated in the study. However, 359 pre-test and 358 post-test questionnaires were collected. Thus, 3 records were excluded from the analysis. The mean (SD) age of the girls was 14.63 (1.15) years.

Most girls identified menstruation as normal physiological process. Most of them were aware of using sanitary pads/ clean cloths and were positive about consultation; in case, there were any problems related to menstruation. However, the girls showed poor knowledge about cleaning of cloths and disposition of pads, cleaning of genital organs, normal pre-menstrual discharge and sexual intercourse. In general, urban girls had better knowledge about MHM as compared to rural girls (Table 1 ).

Table I.Comparison of Knowledge and attitudes about menstruation in rural and urban girls at baseline

\begin{tabular}{|c|c|c|c|}
\hline \multirow[b]{2}{*}{ Question } & \multicolumn{3}{|c|}{ Frequency (\%) of Correct Response } \\
\hline & $\begin{array}{l}\text { Urban } \\
\mathrm{N}=33\end{array}$ & $\begin{array}{c}\text { Rural } \\
\mathrm{N}=326\end{array}$ & p-value \\
\hline Why do you think menstruation occur in females? & $33(100.0 \%)$ & $251(77.0 \%)$ & 0.002 \\
\hline Where does the bleeding occur from during menstruation? & $18(54.5 \%)$ & $111(34.0 \%)$ & 0.019 \\
\hline What do you use during menstruation? & $33(100.0 \%)$ & $297(91.1 \%)$ & 0.074 \\
\hline What do you use to clean used cloth during menstruation? & $18(54.5 \%)$ & $7(2.1 \%)$ & $<0.001$ \\
\hline Where do you dry the washed cloth used during menstruation? & $20(60.6 \%)$ & $263(80.7 \%)$ & 0.007 \\
\hline $\begin{array}{l}\text { How many times should internal parts (external genitalia) be washed during } \\
\text { menstruation? }\end{array}$ & $17(51.5)$ & $151(46.3 \%)$ & 0.57 \\
\hline What will you do for white discharge before 2-3 days of menstruation date? & $12(36.4 \%)$ & $43(13.2 \%)$ & $<0.001$ \\
\hline Which type of vaginal discharge is to be considered as normal? & $0(0 \%)$ & $79(24.2 \%)$ & 0.001 \\
\hline Where should you dispose used sanitary pads? & $4(12.1 \%)$ & $238(73.0 \%)$ & $<0.001$ \\
\hline If you have a problem related to menstruation, whom will you approach? & $22(66.7 \%)$ & $288(88.3 \%)$ & 0.001 \\
\hline How does a girl become pregnant by meeting a boy? & $33(100 \%)$ & $140(42.9 \%)$ & $<0.001$ \\
\hline \multicolumn{4}{|l|}{ True/ False Questions } \\
\hline Menstrual bleeding is waste of our body & $6(18.2 \%)$ & $99(30.4 \%)$ & 0.143 \\
\hline Menstrual blood is harmful & $26(78.8 \%)$ & $167(51.2 \%)$ & 0.002 \\
\hline You can't play during menstruation & $29(87.9 \%)$ & $90(27.6 \%)$ & $<0.001$ \\
\hline You can't go to religious place or activity during menstruation & $1(3.0 \%)$ & $54(16.6 \%)$ & 0.040 \\
\hline You can't go to kitchen during menstruation for 3-4 days & $23(69.7 \%)$ & $64(19.6 \%)$ & $<0.001$ \\
\hline $\begin{array}{c}\text { You can touch everywhere once you wash your hair on } 4^{\text {th }} \text { day during } \\
\text { menstruation }\end{array}$ & $9(27.3)$ & 46 (14.1\%) & 0.045 \\
\hline You can become ill due to abdominal pain during menstruation & $14(42.4 \%)$ & $150(46.0 \%)$ & 0.693 \\
\hline You can't take spicy \& sour diet during menstruation & $15(45.5 \%)$ & $90(27.6 \%)$ & 0.032 \\
\hline You feel weakness in body during menstruation & $3(9.1 \%)$ & $90(27.6 \%)$ & 0.021 \\
\hline
\end{tabular}


A sense of impurity leading to social and cultural restrictions was quite prevalent. Most girls complained of weakness [254 (70.8\%)] and about half [179 (49.9\%)] felt 'unwell' during menstruation. Urban girls showed more liberal attitudes towards the socio-cultural restrictions (Table 1).

The knowledge improved significantly and attained a satisfactory level after the educational intervention except for 'drying of used cloths.' However, the sense of impurity leading to socio-cultural restrictions was quite prevalent (albeit achieved statistical significance) (Table 2).

The girls were shy to discuss about reproductive system or menstruation. During session, when reproductive organs were displayed, students used to put their eyes down. They usually hesitated to ask questions after sessions. Questions were asked by girls who were actively involved in session during interaction and discussion. Majority of girls preferred to approach on an individual basis after the session. Girls approached in group of 2 to 3 girls who had same problems or keen to know. Many girls asked contact number as they felt uncomfortable to share in presence of their classmates.

Four major themes emerged out of the queries of participating girls.

\section{General Physiology of Menstruation}

- Why do discharges occur from lower part?

- What is normal and abnormal discharge from lower part?

- Why is pain associated with menstruation?

- Why do we feel weakness during menstruation?

- What is normal flow of blood during menstruation?

- Is menstrual blood unhygienic (dirty blood)?

Table 2.Impact of an educational intervention on knowledge and attitudes about menstruation in school going adolescent girls

\begin{tabular}{|c|c|c|c|}
\hline \multirow{3}{*}{ Question } & \multicolumn{3}{|c|}{$\%$ of Correct Response } \\
\hline & \multirow{2}{*}{\begin{tabular}{|c|} 
Pre $[\mathrm{n}=359]$ \\
Frequency(\%)
\end{tabular}} & \multirow{2}{*}{\begin{tabular}{c|} 
Post $[n=358]$ \\
Frequency(\%)
\end{tabular}} & \multirow{2}{*}{ P-value } \\
\hline & & & \\
\hline Why do you think menstruation occurs in females? & $284(79.1)$ & $344(96.08)$ & $<0.001$ \\
\hline Where does the bleeding occur from during menstruation? & $129(35.93)$ & $316(88.26)$ & $<0.001$ \\
\hline What do you use during menstruation? & $330(91.92)$ & $344(96.08)$ & 0.018 \\
\hline What do you use to clean used cloth during menstruation? & $25(6.96)$ & $29(8.1)$ & 0.56 \\
\hline Where do you dry the washed cloth used during menstruation? & $283(78.83)$ & $337(94.13)$ & $<0.001$ \\
\hline $\begin{array}{l}\text { How many times should internal parts (external genitalia) be washed } \\
\qquad \text { during menstruation? }\end{array}$ & $168(46.79)$ & $315(87.98)$ & $<0.001$ \\
\hline $\begin{array}{l}\text { What will you do if white discharge before } 2-3 \text { days of menstruation } \\
\text { date? }\end{array}$ & $55(15.32)$ & $210(58.65)$ & $<0.001$ \\
\hline Which type of vaginal discharge is to be considered as normal? & $79(22.00)$ & $274(76.53)$ & $<0.001$ \\
\hline Where do you dispose used sanitary pads? & $242(67.40)$ & $309(86.31)$ & $<0.001$ \\
\hline $\begin{array}{l}\text { If you have a problem related to menstruation, whom will you } \\
\text { approach? }\end{array}$ & $310(86.07)$ & $317(88.54)$ & 0.31 \\
\hline How does a girl become pregnant by meeting a boy? & $173(48.18)$ & $287(80.16)$ & $<0.001$ \\
\hline \multicolumn{4}{|l|}{ True/ False Questions } \\
\hline Menstrual bleeding is waste of our body. & $105(29.24)$ & $162(45.25)$ & $<0.001$ \\
\hline Menstrual blood is harmful. & $193(53.76)$ & $218(60.89)$ & 0.053 \\
\hline You can't play during menstruation. & $119(33.14)$ & $157(43.85)$ & 0.003 \\
\hline You can't go to religious place or activity during menstruation & $55(15.32)$ & $140(39.10)$ & $<0.001$ \\
\hline You can't go to kitchen during menstruation for 3 to 4 days. & $87(24.23)$ & $146(40.78)$ & $<0.001$ \\
\hline $\begin{array}{l}\text { You can touch everywhere once you wash your hair on } 4^{\text {th }} \text { day during } \\
\text { menstruation. }\end{array}$ & $55(15.32)$ & $84(23.46)$ & 0.005 \\
\hline You can become ill due to abdominal pain during menstruation. & $164(45.68)$ & $195(54.46)$ & 0.01 \\
\hline You can't take spicy \& sour diet during menstruation & $105(29.24)$ & $158(44.13)$ & $<0.001$ \\
\hline
\end{tabular}




\section{Body Image}

- What is the treatment for Acne?

- How to increase the height?

- Should we remove pubic hair?

- How and when will my breasts be enlarged?

\section{General Knowledge about Sex}

- How does pregnancy occur?

- What is masturbation?

- Why doesn't menstruation happen to boys?

- Can a girl become pregnant by kissing the boy?

\section{General Physical Complains}

- What is the reason of itching in lower part?

- What is the reason for burning urination?

\section{Discussion}

The adolescent girls of Charutar region of Gujarat showed poor knowledge about MHM. A sense of impurity led to socio-cultural restrictions as perceived by the participants. In general, the rural girls exhibited poor knowledge as compared to the urban girls. The systematic educational intervention that evolved over time improved knowledge regarding MHM adequately. However, the perceptions about socio-cultural restrictions were prevalent even after the intervention.

It is not surprising that a systematic educational intervention improved the knowledge of good MHM and also improved the perceptions about restrictions imposed on menstruating woman by the society to some extent. The taboos related to menstruation and restrictions imposed on menstruating women are common across the globe..$^{1-4}$ The poor knowledge of adolescent girls and need for empowering girls about good MHM in low and middle income countries and India has been identified consistently. ${ }^{2,6-11}$ Due to modernization, socio-cultural restrictions are fading in urban populations but very slowly. ${ }^{7-8}$

Provision of sanitary napkins at an affordable cost and building of toilets under Swachh Bharat Mission definitely provided some respite to adolescent girls especially in rural areas. ${ }^{5,19}$ It is heartening to note that intervention strategies also evolved-from focusing on menstrual hygiene management ${ }^{14-17}$ to reproductive health ${ }^{12}$ to more comprehensive approach. ${ }^{13}$ However, the adolescent health programmes should go beyond reproductive health and adopt a holistic view in addressing adolescent health. This is important as new challenges to adolescent health are emerging across the globe. Even in Charutar region of Gujarat, bullying, ${ }^{20}$ Internet addiction, ${ }^{21}$ mental health issues, ${ }^{22}$ poor physical activity ${ }^{23}$ and the like have been identified over time. The current study incorporated education on nutrition, exercise and Yoga beyond the
MHM and reproductive health though the impact was not assessed.

There have been unflagging efforts to address issues related to adolescent health by Central as well as state governments in the past two decades. Initially, targeted vertical programmes were implemented focusing on reproductive and sexual health with varying success. ${ }^{24}$ It should be noted that any such programme should be culturally appropriate to achieve desired effect and due diligence is required in developing the contents of such progranmes. Some over-enthusiastic managers at UNICEF, India developed material for reproductive health in the form of flip book in 2008-2009. The material contained full body pictures of women and women genital organs. Due to strong community objections, this programme received a severe setback.

As elaborated by Satia J,18 Rashtriya Kishor Swasthya Karyakram (RKSK) is the latest and most comprehensive adolescent health programme launched in 2014 in India. This programme tried to cater to various needs related to adolescent health and include all the stakeholders at least on paper. Some serious systematic efforts to implement RKSK is endorsed by the author.

Albeit a basic framework of the typical adolescent health programme is provided through RKSK, some flexibility for add on components is required based on the context to cover emerging issues like Internet addiction, decreased physical activity, and the like. To achieve this, a greater commitment of all stakeholders is essential. This would also provide opportunity to develop contextual content as well as behavioral change models that work. ${ }^{18-19}$

\section{Conclusion}

Adolescent girls showed poor knowledge and attitudes about menstruation and hygiene. A systematic educational intervention would improve MHM of adolescent girls. A comprehensive and contextual adolescent health model including all stakeholders should be developed to improve health of our future generation.

\section{Conflict of Interest: None}

\section{References}

1. Guterman M, Mehta P, Gibbs M. Menstrual Taboos Among Major Religions. The Internet Journal of World Health and Societal Politics 2007; 5(2): 1-7. Available from: http://ispub.com/IJWH/5/2/8213 [Google Scholar].

2. Dasgupta A, Sarkar M. Menstrual Hygiene: How Hygienic is the Adolescent Girl? Indian J Community Med 2008; 33(2): 77-80. Available from: http://www. ijcm.org.in/article.asp?issn=0970-0218; year=2008;vo 
lume=33;issue=2; spage=77; epage=80; aulast=Dasgup ta [PubMed/ Google Scholar].

3. Sumpter C, Torondel B. A Systematic Review of the Health and Social Effects of Menstrual Hygiene Management. PLOS ONE 2013; 8(4): e62004. Available from: https:// journals.plos.org/plosone/article?id=10.1371/journal. pone.0062004 [PubMed/ Google Scholar].

4. Bhartiya A. Menstruation, Religion and Society. International Journal of Social Science and Humanity 2013; 3(6): 523-527. Available from: http://www.ijssh. org/papers/296-B00016.pdf [Google Scholar].

5. Garg R, Goyal S, Gupta S. India moves towards menstrual hygiene: subsidized sanitary napkins for rural adolescent girls-issues and challenges. Matern Child Health J 2012; 16(4): 767-774. Available from: https:// europepmc.org/article/med/21505773 [PubMed/ Google Scholar].

6. Dudeja P, Sindhu A, Shankar P, Gadekar T. A cross-sectional study to assess awareness about menstruation in adolescent girls of an urban slum in western Maharashtra. Int J Adolesc Med Health 2016; 30(4). Available from: https://www.degruyter. com/view/j/ijamh.2018.30.issue-4/ijamh-2016-0079/ ijamh-2016-0079.xml [PubMed/ Google Scholar].

7. Paria B, Bhattacharyya A, Das S. A comparative study on menstrual hygiene among urban and rural adolescent girls of west Bengal. J Family Med Prim Care 2014; 3(4): 413-417. [PubMed/ Google Scholar].

8. Thakre SB, Thakre SS, Reddy M, Rathi N, Pathak $\mathrm{K}$, Ughade S. Menstrual hygiene: knowledge and practice among adolescent school girls of Saoner, Nagpur district. J Clin Diagn Res 2011; 5(5): 1027-1033. Available from: https://www.ircwash.org/sites/default/ files/Thakre-2011-Menstrual.pdf [Google Scholar].

9. Chothe V, Khubchandani J, Seabert D, Asalkar M, Rakshe $S$, Firke A et al. Students' perceptions and doubts about menstruation in developing countries: a case study from India. Health Promot Pract 2014; 15(3): 319-326. [PubMed/ Google Scholar].

10. Chandra-Mouli V, Patel SV. Mapping the knowledge and understanding of menarche, menstrual hygiene and menstrual health among adolescent girls in lowand middle-income countries. Reprod Health 2017; 14(1): 30. Available from: https://reproductive-healthjournal.biomedcentral.com/articles/10.1186/s12978017-0293-6 [PubMed/ Google Scholar].

11. Van Eijk AM, Sivakami M, Thakkar MB, Bauman A, Laserson KF, Coates S, Phillips-Howard PA. Menstrual hygiene management among adolescent girls in India: a systematic review and meta-analysis. BMJ open 2016; 6(3): e010290. Available from: https://bmjopen.bmj. com/content/6/3/e010290.long [PubMed/ Google Scholar].
12. Rao RS, Lena A, Nair NS, Kamath V, Kamath A. Effectiveness of reproductive health education among rural adolescent girls: a school based intervention study in Udupi Taluk, Karnataka. Indian J Med Sci 2008; 62(11): 439-443. [PubMed/ Google Scholar].

13. Parwej S, Kumar R, Walia I, Aggarwal AK. Reproductive health education intervention trial. Indian $\mathrm{J}$ Pediatr 2005; 72(4): 287-291. [PubMed/ Google Scholar].

14. Shah SP, Nair R, Shah PP, Modi DK, Desai SA, Desai L. Improving quality of life with new menstrual hygiene practices among adolescent tribal girls in rural Gujarat, India. Reprod Health Matters 2013; 21(41): 205-213. Available from: https://www.tandfonline.com/doi/ full/10.1016/S0968-8080(13)41691-9 [PubMed/ Google Scholar].

15. Dongre AR, Deshmukh PR, Garg BS. The effect of community-based health education intervention on management of menstrual hygiene among rural Indian adolescent girls. World Health Popul 2007; 9(3): 4854. Available from: https://www.longwoods.com/ content/19303 [PubMed/ Google Scholar].

16. Sommer M, Caruso BA, Sahin M, Calderon T, Cavill S, Mahon T, Phillips-Howard PA. A time for global action: addressing girls' menstrual hygiene management needs in schools. PLoS Med 2016; 13(2): e1001962. Available from: https://journals.plos.org/plosmedicine/ article? id=10.1371/journal. pmed.1001962 [Google Scholar].

17. Haque SE, Rahman M, Itsuko K, Mutahara M, Sakisaka $K$. The effect of a school-based educational intervention on menstrual health: an intervention study among adolescent girls in Bangladesh. BMJ Open 2014; 4(7): e004607. Available from: https://bmjopen.bmj.com/ content/4/7/e004607.long [PubMed/ Google Scholar].

18. Satia J. Challenges for adolescent health programs:What is needed? Indian J Community Med 2018; 43(5): S15. Available from: http://www.ijcm.org.in/article. asp? issn=0970-0218; year $=2018$; volume $=43$; issue =5; spage=1;epage $=5$; aulast=Satia [Google Scholar] .

19. Patel P, Puwar T, Shah N, Saxena D, Trivedi P, Patel K, et al. Improving adolescent health: Learnings from an interventional study in Gujarat, India. Indian J Community Med 2018; 43: S12-S17. [PubMed/ Google Scholar/ ResearchGate].

20. Patel HA, Varma J, Shah S, Phatak A, Nimbalkar SM. Profile of Bullies and Victims Among Urban School going Adolescent in Gujarat. Indian Pediatr 2017; 54(10): 841-843. Available from: https://www.indianpediatrics. net/oct2017/841.pdf [PubMed/ Google Scholar].

21. Prabhakaran MA, Patel VR, Ganjiwale DJ, Nimbalkar MS. Factors associated with internet addiction among school-going adolescents in Vadodara. J Family Med Prim Care 2016; 5(4): 765-769. [PubMed/ Google 
Scholar/ ResearchGate].

22. Nair S, Ganjiwale J, Kharod N, Varma J, Nimbalkar SM. Epidemiological survey of mental health in adolescent school children of Gujarat, India. BMJ BMJ Paediatr Open 2017; 1(1): e000139. Available from: https:// bmjpaedsopen.bmj.com/content/1/1/e000139 [PubMed/ Google Scholar].

23. Dave H, Nimbalkar SM, Vasa R, Phatak AG. Assessment of Physical Activity among Adolescents: A Crosssectional Study. Journal of Clinical and Diagnostic Research 2017; 11(11): SC21-SC24. Available from: http://jcdr.in/article_abstract.asp?issn=0973-709x\& year $=2017 \&$ volume $=11 \&$ issue $=11 \&$ page $=$ SC21 $\&$ is sn=0973-709x\&id=10870 [Google Scholar].

24. Chauhan A, Chauhan SK, Bala DV. Adolescent Health Programs in Gujarat State-A Case Study. Journal of Medical Science and Clinical Research 2016; 4(10): 13342-13347. Available from: http://jmscr. igmpublication.org/home/index.php/archive/91volume-4-issue-10-oct-2016/1221-adolescent-healthprograms-in-gujarat-state-a-case-study. 